\title{
Research on Protection and Renewal of Macao Historical City from the Perspective of Space Narrative*
}

\author{
Hanmao Liu \\ College of Architecture and Civil Engineering \\ Wuyi University \\ Wuyishan, China 354300 \\ Faculty of Innovation and Design \\ City University of Macau \\ Macau, China 999078
}

\begin{abstract}
The historic city is an important space of the city. It not only witnessed the rise and fall of a city, but also accumulated a complex and rich collective emotional and cultural spirit. Urban space narrative research tend to qualitative analysis rather than quantitative comparison, history of Macao city, for example, by constructing urban history narrative system, introduced in the narrative environment space syntax to quantitative description, narrative space environment space as "figure", street network "bottom", the narrative space and city space structure form organic connection, historical urban space narrative structure and narrative information system, for protecting and renovating historical narrative cultural construction and the city to provide theoretical basis and related Suggestions.
\end{abstract}

Keywords—the historic city; narrative; spatial narration; space syntax

\section{INTRODUCTION}

The Macao historical urban area is a well-preserved architectural complex of Chinese and Western buildings. It currently is the longest preserved, the most intact and the largest in terms of overall size building complex in China. Historical spaces not only record the development and evolution of cities and buildings as the carrier of time and space, but also bear the weight of the urban public activities and residents' daily behaviors, which contain the collective memory and emotion and spiritual and cultural identity of the community people. These historical spaces in the "postheritage" period how to sustainable inherit the architectural heritage culture and to continue the story and memory of the city, which is a subject that needs to be emphasized and discussed in the future.

Spatial research cannot cut the bonds with social relation; otherwise it just simply emphasizes the shaping and excavation of the spatial environment and ignores the social and humanistic factors. As a result, it can only leave over the

*Task project: 2017 University Scientific Research Fund Project of Wuyi University (Project Number: JG201704). "coat" filled with historical culture. The protection and reproduction of space need the continuous emergence of organic behaviors in space. Taking the architectural heritage groups and its foreland in the historic urban area of Macao as the breakthrough point, it is integrated into the narrative dimension with space as the framework. Quantitative explanations are given through spatial syntax to realize the transfer and conversion from nature to society and from real physical space to humanistic spirits in order to fully understand the material space and spiritual connotation carried by the historic space, which expands the train of thought for the construction of historical urban culture and provides support for the protection and renewal of its buildings.

\section{SPACE NARRATION AND SPACE SyNTAX}

Spatial narration means that the narrative body tells stories, events or experiences to the recipients by using various related channel of expression with space material elements as the media. At the same time, the recipients conduct selfinterpretation on the space according to media and different individual knowledge systems ${ }^{1}$. Since the beginning of 1960 s, because western geography has been involved in the research of narratology, the relevant theoretical research of narratology has been re-emphasized, and this gradually has formed a research system in which narratology interacts with various disciplines. This enriches the connotation and extension of urban geography, and the urban space, place, space and environment have also been redefined, which lays a research foundation for the future development of urban geography. And then in the 1970s and 1980s, with the emergence of Henri Lefebvre's spatial theory and Michel Foucault's further interpretation of spatial theory; they jointly declared the arrival of space age.

In the complex process of society and space, social relations project themselves into space and solidify in space, which make space appear in the process, thus producing space.

Guo Xiaoke Research on Narrative Design Method of Urban Open Space [D]. Xi'an: Xi'an University of Architecture and Technology, 2011. 
${ }^{2}$ Space has also been used as a background or container for social development, and social relations have undergone an era change in the framework of space containers. On the other hand, from the perspective of space, Henry Lefebvre proposed that "production of space" replace "production in space". As a space environment for container framework, space participates in complex social relations produced by a purposeful manner. ${ }^{3}$ The narrative researches that relatively long-term bias time and social dimension, and the spatial dimension in the narration begins to receive attention.

Spatial syntax focuses on the relationships between the spatial structure of materialization and the social relationship of non-materialization, and is the theory and method for researching the relationships between spatial organization and human society ${ }^{4}$. Urban space research in the past paid more attention to the urban space and skin texture formed by the development and changes of society, that is, social relations influence and shape the formation of urban space, and the relationships between space and space. For a long time, urban space is simply considered to be the sum total of various social relationships, or the container of era background and urban development. If we think from the perspective of urban spatial cognition, in fact, although space is produced by a purposeful manner, it will also participate in affecting complex social relationships. Bill Hillier and Julienne Hanson described that in their book The Social Logic of Space: "Space factors should be considered in abstract social structures, and social factors should be considered in the material spatial structures. ${ }^{5}$ The relationships between society and space can be considered as two-way interaction, mutual effect and stride forward with each other in the historical development.

\section{RESEARCH CASE OVERVIEW}

Macao is not only a modern capital, but also a city with historical culture. Since its opening of ports several centuries ago, the convergence of Eastern and Western culture and the coexistence and inheritance of urban heritage have made Macao form its unique Chinese and Portuguese cultural characteristics and urban characteristics. As early as before the Portuguese came to Macao, Fujianese, who made a living with fishing and business, were the earliest developers and builders of the island. They brought Mazu worship to this place and built Chinese religious buildings such as A-Ma Temple and Shuri Kannondo Temple ${ }^{6}$. Since the mid-16th century, the Portuguese gradually have settled here to develop ocean-going trade because Macao's ban on maritime trade have lessened, thus ushering in a golden century of development in history. During this period, the Portuguese established Saint Paul College and a series of church buildings, which made Macao become the outpost for Europeans to study language and culture before they entered China for missionary work in the

\footnotetext{
2 Henri Lefebvre. The Production of Space[M]. Oxford: Blackwell, 1991. Ditto

Bill Hillier, Duan Jin. Space Syntax and Urban Planning [M]. Southeast University Press, 2007.

5 Bill Hillier, Julienne Hanson. The Social Logic of Space [M]. Cambridge University Press, 1989.

6 Macao Notes
}

next few hundred years. The fortresses and churches completed on the top and main mountain ridge contours became the skeleton of urban spatial development in the future. ${ }^{7}$ Macao has integrated Chinese and Western culture and architectural features in its long history of evolution. So far a considerable number of urban architectural heritage groups have been well preserved in the city, which makes Macao become an important part of the world heritage. The multicultural characteristics of Macao's architectural heritage constitute the unique landscape and urban spirits of Macao's urban culture.

Macao World Heritage Site is located on the Macao Peninsula that is composed of 30 heritage spaces (including 22 architectural heritage sites and 8 adjacent forelands) located in historic old urban area. As a result, the research object is also limited to the heritage space in this historic urban area and its adjacent urban street networks, hereinafter referred to as historic urban area. In order to investigate the historic urban area, this paper sorts out the evolution and changes of the space of the historic urban area through literature and official records; from the sociological perspective, this paper focuses on recording the daily behaviors and activities of residents in the space; from the spatial physical and environmental aspects, this paper investigates the spatial distribution patterns, spatial restriction modes, and the relationships with the surrounding environment.

\section{CONSTRUCtion OF Spatial Narrative System of HISTORICAL URBAN AREA}

The narrative system of historical urban space can be divided into narrative patches, narrative themes and narrative corridors. The narrative space focuses on the research of material space defined by the narration, including architecture and related space areas defined by it; the narrative themes focus on the daily life of the people, festival and worship activities etc.; the narrative corridors focus on the spatial dimensional axis of the structural organization and contact the narrative spatial elements in the same area.

\section{A. Narrative Patches}

1) Spatial classification: According to the research status, there are 22 buildings and 8 forelands in the historic urban area of Macao. The layout can be roughly divided into the style of enclosed, single and open.

Enclosed styles are common in temples and churches with a long history, a rich historical profundity and a larger scale and volume, such as A-Ma Temple, Kao Hall, Fengshun Hall, and Saint Joseph Monastery. Enclosed style can also be called a courtyard-style space, which defines a clear spatial scope in the form of a wall enclosure. In the Chinese-style temple building courtyards, the single buildings with different sizes and spatial functions are sequentially unfolded along the axis, or the plane layout is unfolded in situ according to the characteristics of the terrain. The interior spatial layouts of the Western-style church are more traditional with the plane being

Liu Xianjue Xuzheng Religious Architecture of Macao [J]. Huazhong Architecture, 2002 (06): 84. 
in the form of Western Latin Cross or geometric style, and the wall enclosure defines the geometric regular form of the building. The grounds enclosed by the courtyard create a background for the creation of the spatial plots, thus providing a possibility for diverse activities outside the buildings.

In the signal layout, the external spaces of the temple building are limited by the surrounding environment. The overall building size is generally small, and there are few site spaces for people to rest and hold outdoor various activities, such as the Pagode Sam Cai Vu Cun and the Nezha Temple. The internal spatial pattern changes of these temples are simple, and generally only one main shrine is dedicated to the worship with simple pilgrimage. The single buildings of Western-style church, including St. Augustine Church, Duomo di Siena and Holy House of Mercy, have no wall screenings on the outside of these buildings, however, such churches generally have front spaces for the joint use of churches or several surrounding buildings, such as the Largo de Santo Agostinho of the St. Augustine Church, the front square of lobby and the front square of the Rose Hall.

The open-style spaces are more common in the front space of the churches, such as the A-Ma Temple and its front spaces, Largo de Santo Agostinho, the foreland of the Rose Hall, the foreland of the lobby, the Memorial Square of Society of Jesus (the Ruins of St. Paul, the former St. Paul Church's ruins), the foreland of the white pigeon nest and others. The front spaces that are population distribution on weekdays and hold the celebration ceremonies are wide, and connect the churches, buildings or street roads in the blocks.

2) Spatial distribution: Before the opening of commercial ports in Macao, temples and ancestral temples were scattered in the peninsula. Since the Portuguese landed on the island for commerce, the city walls built by the Portuguese had gradually divided Macao into an urban pattern that lived in by "inside the city " and "outside the city" ${ }^{\prime}$. Later, a series of churches and front spaces built by the Portuguese formed an important node in the city, which resulted in the formation of the early historical urban area of Macao. The temples and churches built in different historical periods in the urban area, from the foreland of A-Ma Temple in the south to Saint Andoni Church in the north, are mostly centered in the urban area on the left side of the Macao Peninsula, which roughly confirm that the distribution of religious buildings in Macao roughly coincide with the main residential areas of the Chinese and Portuguese residents and the administrative division centers of the two countries in history, and reflects a feature that the cogovernance of land by two countries.

3) Spatial influence scope: Investigation and comparison find that the enclosed-style and open-style spaces mostly are located on both sides of the urban road with high and visual accessibility, which generally have obvious landmark marks and surrounding buildings unfold around it. However, the singles-style spaces generally deviate from the main road network trunk of the city with located in urban streets, needed to walk into and being good connection with community

Wu Yao. Research on the Construction Transition in Late Modern Macao [D], Southeast University residents. As a whole, enclosed-style and open-style spaces have a wider impact on the surrounding streets.

\section{B. Narrative Theme Expression}

The temple and church buildings in the city are mostly located in residential blocks. It can be said that the belief space is "born" in the blocks and "grow" in the blocks. In the long axis of time as a factor, it has already been integrated with the urban spaces and closely linked with the residents' life, work, recreation and entertainment. As an important part of urban public spaces, this kind of historical space records various activities happened in the everyday and festival day of cities and blocks, which accumulates complex and rich collective emotions and urban spatial memory materials.

The activities carried by belief space on weekdays mainly include blessings and worship, cultural activities and social services.

1) Blessings and worship: Worship activities refer to the tradition of worship activities to gods, ancestors and others at a specific time and place. The important significance of sacrifice lies in praying for blessings, thanks and disaster relief. Under the impetus of Macao's polybasic cultures, polybasic religious beliefs have become an important part of local cultures, and people with religious beliefs are much more than those without ones. Blessings and worship is the most basic and common behavioral habits in urban belief spaces. Perennial inflow and outflow of people, prayers and continuous incense have become part of the daily behavioral activities of urban residents and visitors at home and abroad. In terms of income and expenditure of life, joy, anger, sorrow and pleasure, people are used to go to church to chant sutra and tell, or worship at large and small temples with offering incenses. People's dialogue and communication with gods is the most natural care and comfort.

2) Cultural activity: In the religious festivals, believers and the public will gather together to share the same moral sentiments, consolidate the beliefs and collective identity of the believers, and promote the unity of the religious community, which forms a stable and orderly belief community. In addition, the collective behavioral activities that are spontaneous because of beliefs have also played a significant role in enhancing the vitality of the blocks and the image of the urban culture.

Under the multicultural space of Macao City, there are quite a large number of local belief activities, which can be divided into two categories: religious parades and cultural and recreational performances. For example, Mazu's birthday is celebrated on the 23rd of March in the lunar calendar, and a grand celebration of the birthday is held in the A-Ma Temple and in the front spaces. The majority of Macao residents and believers from Hong Kong, Taiwan, Japan, South Korea and Southeast Asia make a deafening sound of gongs and drums and act as false dragons and lions. They pray Mazu that her grace can spread the Four Seas, the country is prosperous and the people are at peace, good weather for the crops, social stability and Macao in blessing. For another example, the Walked Fish Drunken Dragon Festival - Macao unique local intangible cultural heritage, which is held every year on the 8 th 
of April in the lunar calendar in the Pagode Sam Cai Vu Cun, in the Senado Square and other belief spaces. It also holds drunk dragon tour celebrations in accordance with the usual practice, and distributes dragon boat head meals to the public to celebrate the memory of ancestors and pray for peace; on the same day, there are traditional Buddha's birthday to celebrate the birth of Buddha and the parade celebrated activity to celebrate the birth of Tam Kung that is the Taoist sea god. The parade celebration of the holy images of Jesus originating from the West is an extremely characteristic Catholic activity in Macao. The Christians gather in the lobby of the bishop to attend the black funeral ceremony of Jesus. The priest in purple paraments is the forerunner, the clergymen carries the statue of the holy images of Jesus, and they start from the lobby of the bishop, pass through the Senado Square, the Banzhang Hall and the travessa do bispo return to the cathedral, which is an unprecedented event. The Macao Light and Film Festival, which fully demonstrates the blending of modern science and technology with historical culture, covers the innovative light and shadow technology, light and shadow vocal music and interactive elements technology into many religious buildings and front squares in the historic urban area, and re-deduces Macao's historical stories; Macao's annual Latin City Color Intrigue Parade where artistic groups that come from local place, Latin-speaking countries and at home and abroad jointly perform art tours, and people passing through the historic urban buildings light up the urban space color with colorful parades.

3) Social function: Many historical spatial sites in the urban area have taken into account different social service functions, such as the Catholic Church, clergy help those in need in hospitals, schools, homes for the elderly and refugee centers, and have done a lot of efforts for charity. As the oldest social charity institution in Macao, the Holy House of Mercy has the main function of social charity, relief to people in need and enlightenment to persuade; the overwhelming majority of local churches provide venues for newly-married couples to hold weddings, as well as some churches are oriented to all groups of church moral education, persuasion and other things. Temples located in street spaces often prepare vegetarian food and social help for public in need.

\section{Narrative Corridor}

The narrative corridor connects the narrative spaces in the historical urban area in the spatial dimension, which makes it possible to promote the spatial behaviors established above the social relationship. At the same time, the narrative corridor sort out and integrate the narrative elements such as the subject, the carrier and the plot of spatial narration, which have an intuitive and comprehensive understanding of spatial narration.

1) Spatial occupation of events: The multiple features of Macao's culture have made historic buildings, foreland and other spaces a site for all kinds of folk activities and festival events. In the historical urban area, daily activities are concentrated in the areas with the religious space as its core, its affiliated space and the street space within the radiation (see "Table I"). The survey finds that festival activities are generally based on parade, which a certain architectural space is the core occurrence point, and the community street space is used as the series connection, and then conduct tour radiation to the other belief spaces behind and its foreland, and which is easy to form gathered and dispersed people in a short time with the large radiation range and the long duration. As a result, it is easy to form the collective memory and cultural experience of urban space, and even cultural identity. For example, the holy image parade of Our Lady of Fatima in the Rose Hall, the holy image parade of the Jesus in the lobby, the excursion activity of Nezha in the Nezha temple and the Walked Fish and drunken dragon parade in the Pagode Sam $\mathrm{Cai} \mathrm{Vu}$ Cun. In the event of civil activities, it can be divided into two forms of spatial convergence and front convergence. The event activities in the space aggregation, the scene of action and the scope of influence are generally limited to the inside of the space or the scope of less contact with the outside, such as the music and dance performances in the church; because of the close proximity to the surrounding buildings, environment, and blocks, the event activities in the front square are open and inclusive, which it is also easy to form gathered people in a certain period of time. At the same time, the radiation range is much larger and it is easy to produce collective memory, cultural experience and identity, such as the Latin Color Intrigue Major Parade in the Senado Square and various types of exhibitions in the Ruins of St. Paul, etc.

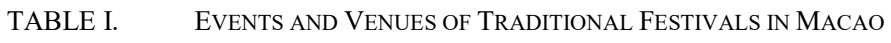

\begin{tabular}{|l|l|}
\hline \multicolumn{1}{|c|}{ Event Occupation Space } & \multicolumn{1}{c|}{ Activity Event } \\
\hline Rose Hall & $\begin{array}{l}\text { Macao Orchestra performed in Chinese and Western concerts; Italian Sicilian Sacred Music } \\
\text { Performance; various kinds of group music and vocal music at home and abroad; }\end{array}$ \\
\hline Senado Square - the Chapel of Our Lady & Macao's annual Latin City Color Intrigue Major Parade \\
\hline Ruins of St. Paul & $\begin{array}{l}\text { Intangible Cultural Heritage Exhibition; Japanese Drama Performance; Macao Light and Film Festival } \\
\text { Performance; }\end{array}$ \\
\hline Senado Square & $\begin{array}{l}\text { China's traditional festival activities; French Summer Solstice Music Festival; Guangdong intangible } \\
\text { cultural heritage "Liannan Yao Shaikh Drum Dance" New Year song and dance performance; }\end{array}$ \\
\hline $\begin{array}{l}\text { Ruins of St. Paul, Rose Hall, A-Ma Temple } \\
\text { and other world cultural heritage }\end{array}$ & The activities of small guides of Macao's cultural heritage; \\
\hline $\begin{array}{l}\text { Pagode Sam Cai Vu Cun(Temple of Guanyu)- } \\
\text { Senado Square-community street space }\end{array}$ & $\begin{array}{l}\text { Every year on May 14th of the lunar calendar, the state and Macao intangible cultural heritage's "Fish } \\
\text { Driving Drunk Dragon Festival" Parade }\end{array}$ \\
\hline A-Ma Temple & $\begin{array}{l}\text { Every year on March 23 of the lunar calendar, } \\
\text { "Mazu Faith and Customs". }\end{array}$ \\
\hline
\end{tabular}




\begin{tabular}{|l|l|}
\hline \multicolumn{1}{|c|}{ Event Occupation Space } & \multicolumn{1}{|c|}{ Activity Event } \\
\hline Nezha Temple & $\begin{array}{l}\text { Every year on May 18 of the lunar calendar, the state and Macao intangible cultural heritage's "Nezha } \\
\text { Faith and Customs". }\end{array}$ \\
\hline Lobby-Senado Square-Rose Hall & Every year on the second Friday of April, the holy image of Jesus parade. \\
\hline $\begin{array}{l}\text { Rose Hall-Largo de S.Domingos- small } \\
\text { Chapel of our lady }\end{array}$ & Every year on May 13, the Holy Image of Our lady of fatima parade \\
\hline Dom Pedro V Theatre & Various Chinese and foreign music and vocal music performances at home and abroad; \\
\hline Monte Fort & Various Chinese and foreign ethnic customs outdoor music opera performances \\
\hline Casa de Lou Kau & Suzhou Pingtan; Guizhou Folk Crafts Exhibition; various folk craft workshops; \\
\hline Robert Hotung Library & $\begin{array}{l}\text { Central Library Collection Poster Exhibition; Drama Performance; Paper and Paper-Making } \\
\text { Technology Seminar;Various folk craft workshops; }\end{array}$ \\
\hline Casa da Cheang & $\begin{array}{l}\text { Belgian shadow play, Spanish puppet opera; Chinese music concert; ethnic music performances; } \\
\text { various folk craft workshops; }\end{array}$ \\
\hline
\end{tabular}

It is found that after comparison the event activity takes place in the space-lane-space parade activity and the forelandstreet exhibition activities, which are better than the exhibition activity only held in the interior of the space in terms of its influence, group participation, cultural experience and identity, as well as the urban collective memory space formed by it.

2) Narrative space and street relationship: The research on the space of historic urban area can be carried out quantitative analysis from the perspective of the accessibility of road and line-of-sight and the space of streets and lanes in which it is located. According to the above classification of architectural space, 12 representative sites are selected as the research object and then extract an important representation of the narrative environment of historical space from comparative analysis of three angles of road integration, connectivity, visual depth and intelligibility.

a) Integration degree: Integration degree reflects the degree of convergence and dispersion of researching space in the overall environment, which can measure the gravity of accessible paths between spaces. The higher the integration degree is, the better the accessibility is. When the integration value is in the range of 1-0.6, the graph value changes from red to orange, which indicates that the region has a high degree of convergence and strong accessibility; when the integration value is below 0.6 , the graph value gradually becomes blue to dark, which indicates that the research area is relatively discrete and low accessibility.(See "Table II")The comparative analysis shows that the three types of space in historical blocks are all located in the topological center of the street network space. When the average integration degree is within the range of 0.6-0.9, the road axes connected by the historic spaces and the blocks are biased towards red and orange, which indicates that they are closely connected with the blocks with high accessibility and will promote people to conduct diversified behavioral activities that will attract more convergence of commercial services. On the other hand, it indicates such historical space has special historical significance in the street network.

TABLE II. Integration Degree ANALysis of PAgOde SAM CAI Vu Cun AND Rose HaLl

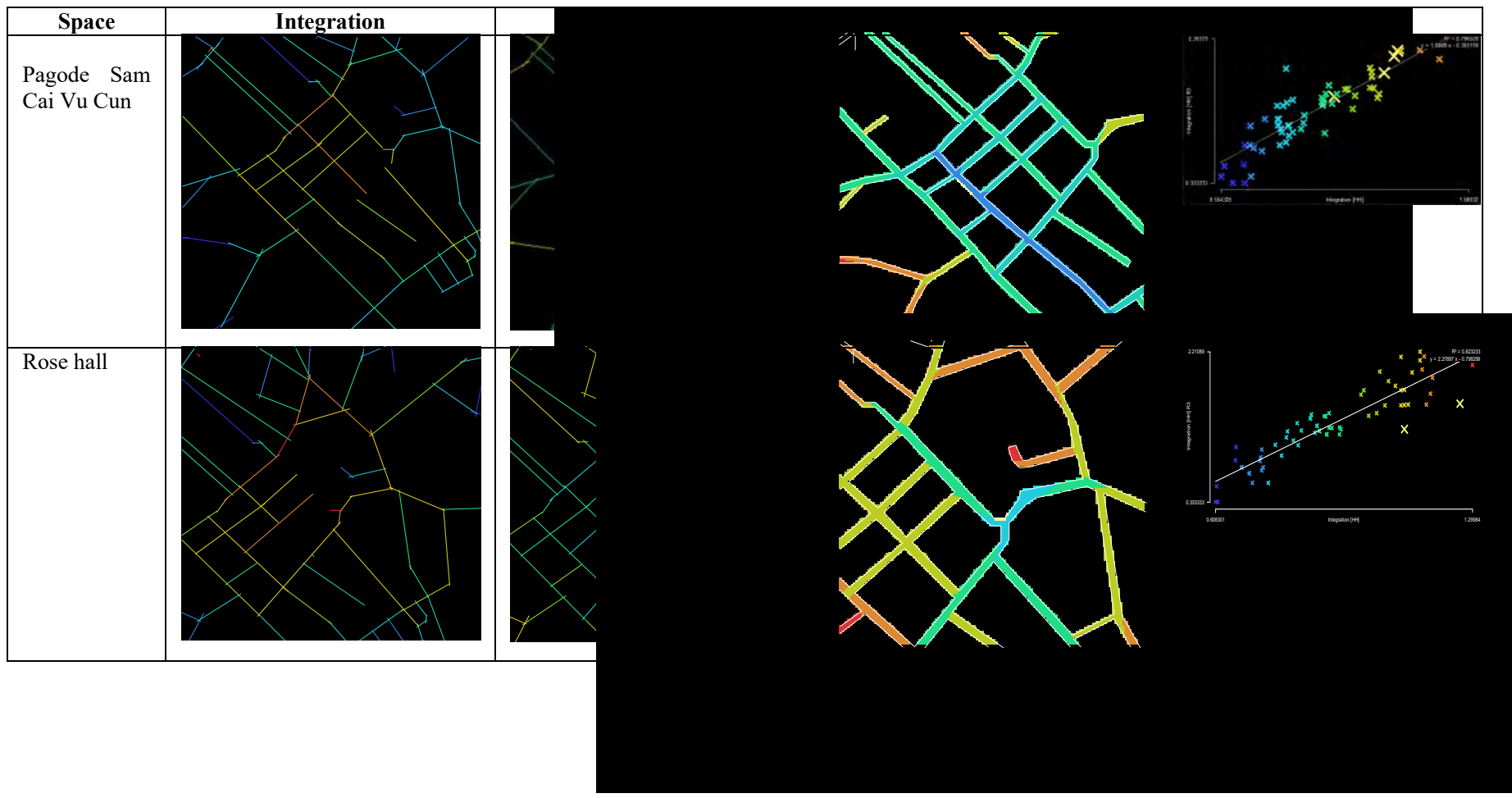


b) Connectivity: The connectivity is centered on the preference set of the space, and inspects and examines the depth of the overall spatial network. It corresponds to the integration, which involves from the connectivity between space and space and researches all the intersected space in the environment with all other fields. The location has high connectivity value, which indicates that the space penetration is better and the path from other places to the space environment is also easier to reach. The comparison shows that the single-style space has the lowest road connectivity, while the connectivity of enclosed-style and open-style spaces is significantly improved, which shows a increase between the research space and the openness of the block and its relationship with road network is more closely connected, and the spatial penetration is more and more improved.

TABLE III. CONNECTIVITy ANALysis of IGREJA DE So LOURENO AND CASA DA ChEANG

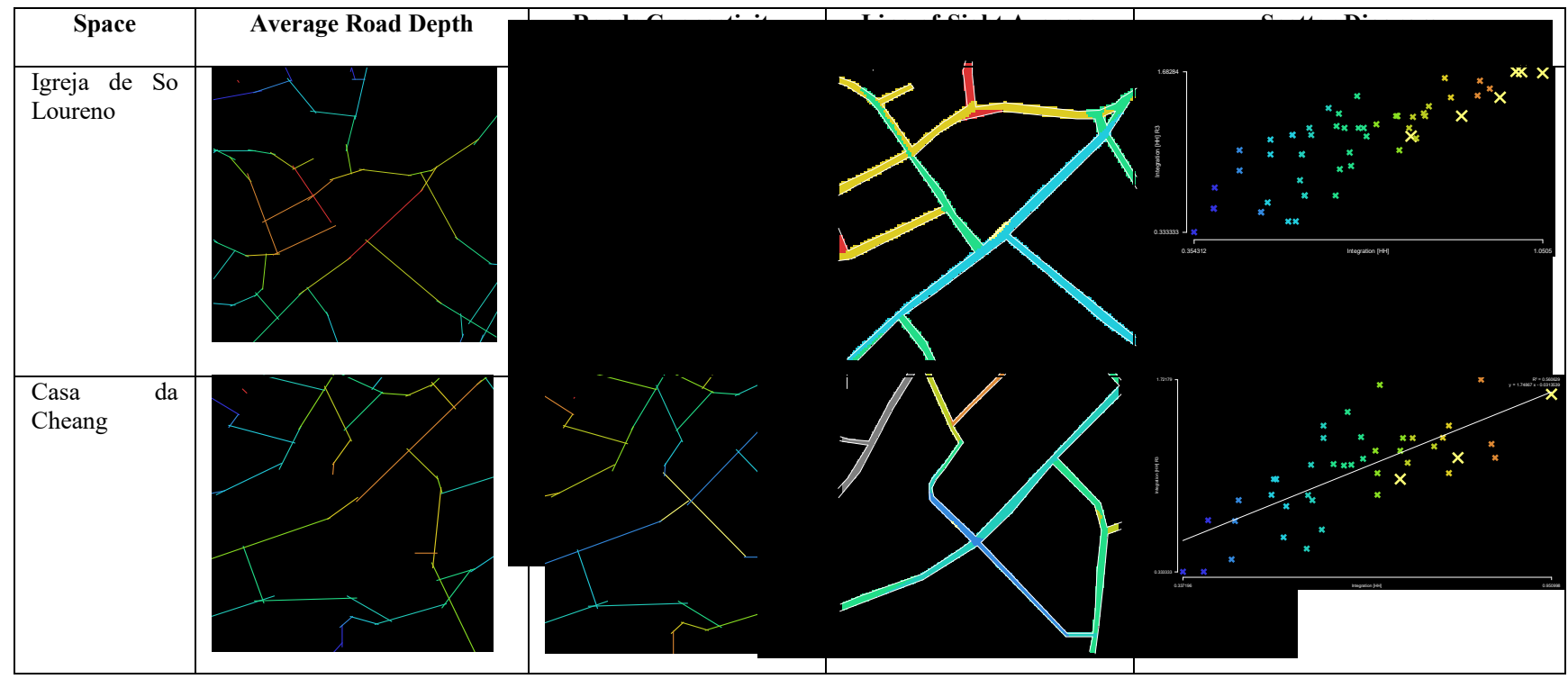

c) Line-of-sight integration: Through the comparison of line-of-sight integration, the degree of integration is different based on the different spatial structural organizational forms within the buildings. Single-style and open-style spaces have better line-of-sight integration. The single-style buildings are mostly located in the corner of the street, which is easy to form a wider visual field and an open front space; while the open-style spaces itself occupy the road nodes, which connect the surrounding buildings and road networks with strong spatial images and commemorative significance. Enclosed-style squares that use walls and fences define a closed interior space, which the line-of-sight is also limited to a small scope of spatial entrance. At the same time, due to the different enclosed materials, such as railings and other transparent enclosed materials, the line-of-sight integration is better than enclosed-style square with a solid wall.

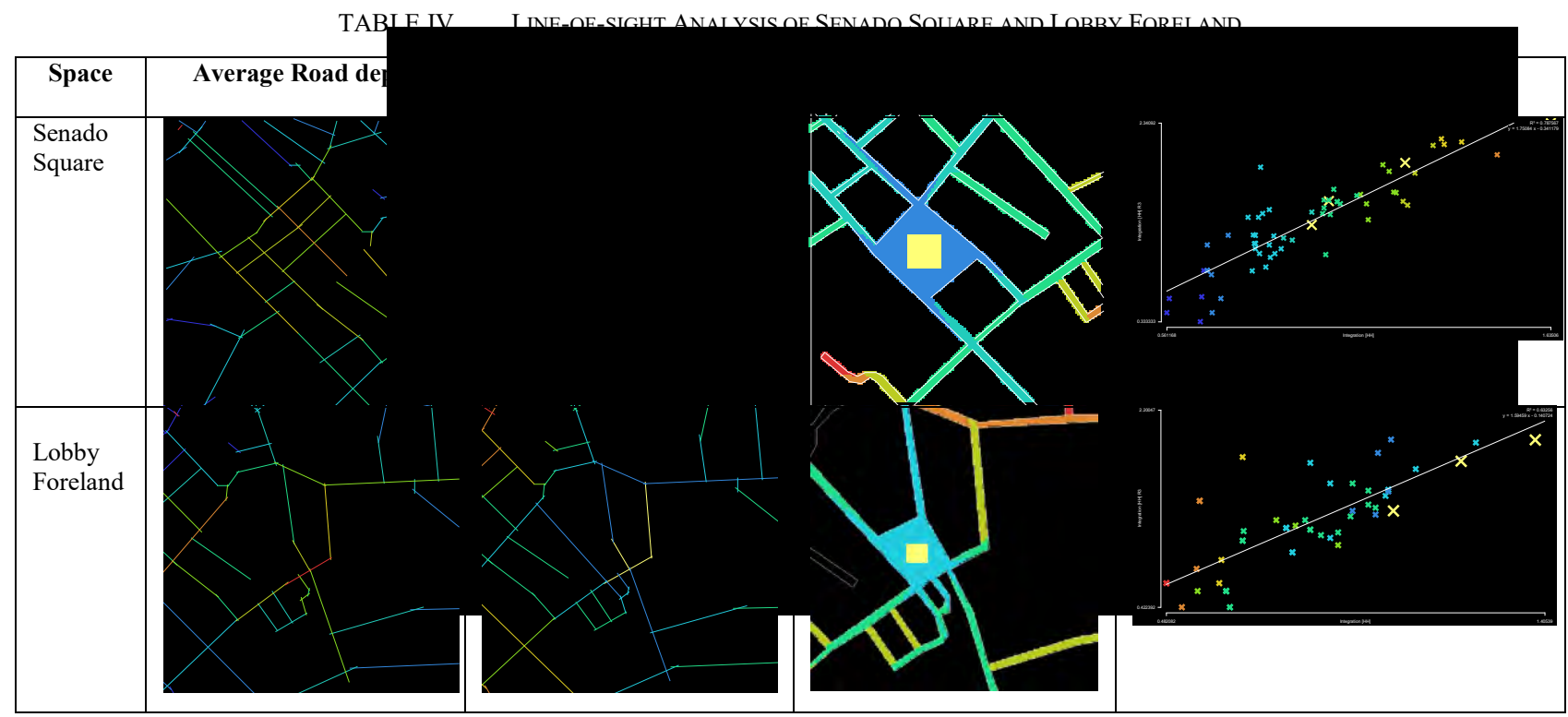


d) Intelligibility: In order to further explain the relationships between the historical space and within the range of the blocks, the intelligibility is used to analyze the location and the street environment. The research examines the recognizability of the spatial environment, that is, the "intelligibility" of space - the degree of synergy with its urban background. Historical urban area of Macao9(yellow), the scatter distribution is linear, and the whole is floating up and down along the regression line, which indicate that the research space in the historical urban area is highly understandable, the integration of urban image formation is high, and the integration degree is better than the integration degree of the Macao Peninsula.

The open-style spaces have the highest intelligibility, and the research points are mostly above the regression line, which indicate that the open-style spaces have outstanding cognitive significance and easy to form the image space of the urban area. The open-style spaces represented by the foreland are a better gathering of buildings, streets and people, which it is easier to promote the formation of public activity space for citizens and commercial trade sites around the spaces. Secondly, the intelligibility of single-style space is higher than that of enclosed-style space because it is more closely connected with the surrounding street and road networks and the building space environment and street integration are also better, which indicate that the intelligibility of the single-style is better than that of the enclosed-style in the two spatial environment of architecture of urban streets, so the images formed by it are better than the enclosed-style space.

\section{CONCLUSION}

Taking the historical urban area of Macao as an example, this paper refines the narrative elements and representations of historical urban space from the perspective of spatial narration, explores the features of urban spatial form through spatial syntax, and hopes to provide theoretical basis and relevant suggestions for the construction, protection and update of narrative culture in historical urban areas.

- Because most of the historical buildings and foreland in the historical urban area are located in the residential and business area, they are the beginning of the daily life of the old town residents, and also an important node of the tourist routes with better space and line-of-sight integration. At the same time, as an important part of the urban public space, the topological central position of the street network space has spawned the diversification of behaviors of different groups of people, which will attract more commercial service convergence and diversified cultural and recreational activities. While the historical urban areas carry rich collective emotions and urban spatial memory materials, and it also

9 The historic city of Macao: In consideration of the large historical urban area, the statistics will not consider the remote points outside the central area, such as the A-Ma Temple, the Holy Virgin and Snowfield Palace. greatly outside extend the spatial influence radiation range.

- $\quad$ Sites with different forms, functions and levels have corresponding spatial narrative environments. Through the spatial organization rules of the building — the foreland - the road, the veins of the historical city have been organized. The single-style, enclosed-style and open-style spaces correspond to different urban street network level due to their different architectural forms and site functions, which organize their own space activities in their respective fields, thus affecting different groups of people.

- The integration of urban public space and residents' cultural and recreational activities is an important expression mode of spatial narration. The historical buildings and front space in the urban area have become an important place for cultural and recreational activities. The effective combination of activities and different spaces constantly injects vitality into the city and brings people different sensory experiences to form a special imagery of a city or a place, which forms the collective memory and cultural experience of urban space.

- Improve spatial integration, explore spatial events, and deepen partial spatial intelligibility. For spaces with low integration in historical urban areas, such as partial single and enclosed spaces, the overall space imagery can first be enhanced by optimizing or re-planning its path grid structure to enhance its spatial accessibility. Second, it can regain spatial historical rudiment, that is, the second meaning of spatial narration - the recipients themselves reinterpret from the narrative cognition and the narrative medium, and then creates new stories with the clue of "space-event-people" to enhance the spatial image.

- Through the optimization of the road grid structure, enrichment of the urban commercial form layout of the historical urban area and diversification the spatial activities, a part of historical building spaces that the citizens and tourists to relatively few participate in are updated and activated and a part of relatively fragmented historical spaces are reintegrated, thus improving the touring quality and city imagery.

\section{REFERENCES}

[1] Guo Xiaoke. Research on narrative design method of urban open space [D]. Xi'an: Xi'an University of Architecture and Technology, 2011. (in Chinese)

[2] Henri Lefebvre. The Production of Space[M]. Oxford:Blackwell, 1991. (in Chinese)

[3] Ditto .

[4] Bill Hillier, Duan Jin. Space Syntax and Urban Planning [M]. Southeast University Press, 2007. 
[5] Bill Hillier, Julienne Hanson. The Social Logic of Space[M]. Cambridge University Press, 1989.

[6] Yin Guangren, Zhang Yulin. Macao Notes [M]. National Library Press, 2010. (in Chinese)

[7] Liu Xianjue, Xu Zheng. Religious Architecture in Macao [J]. Huazhong Architecture, 2002 (06): 84. (in Chinese)

[8] Wu Yao, Research on the Transformation of Macao's Modern Late Construction [D]. Southeast University, 2004. (in Chinese) 